\title{
DETERMINATION OF MAGNESIUM BY THE TITAN YELLOW AND AMMONIUM PHOSPHATE METHODS
}

\author{
BY \\ F. W. HEATON \\ From the Medical Research Council Unit for Metabolic Disturbances in Surgery, the General Infirmary, Leeds
}

(RECEIVED FOR PUBLICATION MARCH 17, 1960)

\begin{abstract}
The ammonium phosphate and Titan yellow methods for determining magnesium have been investigated, and improvements to both techniques are presented. The Titan yellow method is shown to be subject to interference which makes it unsuitable for the analysis of blood cells, food, and faecal materials, and may also affect its reliability with pathological samples of serum and urine. The relative insusceptibility to interference of the ammonium phosphate method makes it more reliable than the Titan yellow method with pathological specimens, and slight modifications permit the use of the same basic procedure with blood, urine, and solutions of food or faecal ash.
\end{abstract}

The wide variety of methods which have been employed for the determination of magnesium in serum serve to illustrate the fact that no technique is completely satisfactory. Methods which may be carried out directly on diluted serum, in some cases after deproteinization, include combination with dyes such as Titan yellow and Eriochrome black T, titration with ethylene diamine tetra-acetic acid, and flame photometry. Other methods involve the initial separation of magnesium, usually as the insoluble magnesium ammonium phosphate, followed by colorimetric estimation of the phosphate in this precipitate. Despite the variety of these techniques, very few have been developed to permit the determination of magnesium in clinical materials other than serum.

Detailed investigations of magnesium metabolism require a method which is suitable not only for the determination of serum and plasma magnesium, but which may also be applied to the estimation of magnesium in urine, blood cells, and acidic solutions of food or faecal ash. These considerations led to the detailed study of methods based on two wellestablished principles which are widely employed for the estimation of magnesium in serum.

\section{Titan Yellow}

This method depends on combination between Titan yellow and magnesium hydroxide to produce an orange-coloured lake, but unfortunately the resulting increase in colour is comparatively small compared with the colour of the free dye. The procedure developed by Neill and Neely (1956) is to be preferred to the techniques described by Orange and
Rhein (1951) and Andreasen (1957), as it produces a higher ratio of colour intensity/blank, but the method may be improved by introducing the following modifications:

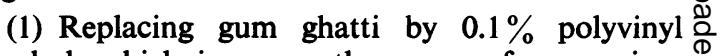
alcohol, which increases the range of magnesium $\cong$ concentration over which the calibration curve is $\overrightarrow{\overrightarrow{0}}$ linear.

(2) Treating the standard magnesium solutions with deproteinizing reagents in the same manner as the test samples, thus allowing for the effect of these reagents on the intensity of colour developed.

(3) Increasing the accuracy of the final stage by measuring the colour produced in cells of $2 \mathrm{~cm}$. light path with a spectrophotometer at $550 \mathrm{~m} \mu$.

The calibration curve must be constructed with 0 each series of determinations as the intensity of colour produced varies slightly from day to day and decreases progressively with increasing age of the Titan yellow solution. The method is very sensitive? to any trace of contamination, but good reproduci- $N$ bility can be maintained by routine cleaning of the tubes used for colour development with chromic acid.

This method is normally satisfactory for the analysis of serum and urine, but allowance must be $\frac{}{\Phi}$ made for the calcium content of test samples as $\stackrel{\mathcal{C}}{?}$ described by Neill and Neely. Although some Titan 0 yellow techniques are apparently unaffected by the 0

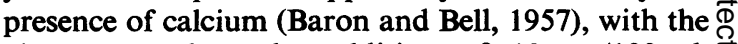
above procedure the addition of $10 \mathrm{mg} . / 100 \mathrm{ml}$. $\frac{\vec{D}}{\alpha}$ calcium to a solution containing $2 \mathrm{mg} . / 100 \mathrm{ml}$. $\frac{\varrho}{\sigma}$ magnesium raises the apparent magnesium content by $7 \%$. 
However, interference studies have shown the method to be affected by many substances besides magnesium, and this restricts its use with materials other than serum and urine. The depression of colour development produced by iron, which was reported by Orange and Rhein, has been confirmed in this laboratory, and a similar effect has been observed with citrate; the apparent magnesium content of serum is lowered by $15 \%$ in the presence of $50 \mathrm{mg}$./ $100 \mathrm{ml}$. citric acid. Gillam (1941) and Otto and Otto (1941) have demonstrated the potential interference of phosphate, ammonium, and many other cations, but the concentration of these ions in serum and urine is usually insufficient to produce inaccuracy. Recently Barker, Elkinton, and Clark (1959) have reported inaccuracy caused by the presence of gluconate and mercurial diuretics.

\section{Magnesium Ammonium Phosphate}

Several micro-modifications of the classical ammonium phosphate precipitation technique for determining magnesium after the prior removal of calcium have been developed. The method for estimating serum magnesium described by Simonsen, Westover, and Wertman (1947) is suitable with the following modifications:

(1) The calcium oxalate precipitate is washed once with $2 \mathrm{ml}$. of $2 \%$ ammonium hydroxide and the washings added to the original supernatant, thus preventing the loss of $4 \%$ magnesium by adsorption on the calcium containing precipitate.

(2) The magnesium ammonium phosphate precipitate is allowed to form overnight; although two hours normally suffice, complete precipitation may take longer with some pathological specimens.

As the preparation and washing of the magnesium containing precipitate rather than the precision of the final colour measurement is the stage limiting the ultimate accuracy of the method, the molybdivanadate method for estimating the phosphate content of this precipitate (Simonsen, Wertman, Westover, and Mehl, 1946) is preferred to the molybdate I and II methods of Fiske and Subbarow (1925); the greater stability of the colour produced with the former method more than outweighs the greater sensitivity of the latter. The calibration curve constructed from theoretically equivalent phosphate solutions is exactly reproducible, but it is desirable to include both a blank and a standard magnesiumcalcium-containing solution with each series of determinations in order to check the absolute accuracy of the method. Optimum accuracy is obtained with samples containing 20-160 $\mu$ g. magnesium, and it is undesirable to use more dilute specimens as difficulty in manipulating the small amount of precipitate may lead to low results.

The same basic procedure can be employed for the determination of magnesium in specimens other than serum. After laking with water the magnesium content of blood cells is estimated in the same way, the results obtained being in agreement with those from ashed cells. The analysis of urine and food or faecal ash requires preliminary adjustment of the $p H$ for precipitation of calcium oxalate. This is achieved by adding $20 \%$ sodium acetate solution dropwise to the acidified sample until the neutral point of methyl orange is reached, when the estimation is completed as for serum.

Although the method is rather slow and laborious, routine use over a period of one year has shown it to produce satisfactory results with an average reproducibility of 2 to $3 \%$.

Apart from calcium, which is initially removed as the oxalate and may thus be determined readily by titration with permanganate, the only substance known to interfere with this method in the concentrations at which it may occur in clinical material is iron. Erroneously high results are obtained if more than $500 \mu \mathrm{g}$. of $\mathrm{Fe}^{3+}$ is present in the sample assayed, but this amount is unlikely to be encountered except in samples containing more than $0.5 \mathrm{ml}$. of ashed blood cells.

\section{Comparison}

Serum and urine from a small series of normal individuals have been analysed simultaneously by both methods. The results with serum indicate a systematic difference, the ammonium phosphate technique consistently yielding results $5-7 \%$ higher than those given by the Titan yellow method. However, with urine the differences between the methods appear to be random.

Although comparisons have not been made with a wide variety of pathological specimens, the Titan yellow method has been found to under-estimate seriously the magnesium content of urine from patients receiving Shohl's citric acid/sodium citrate solution (Albright, Consolazio, Coombs, Sulkowitch, and Talbott, 1940) and the method is therefore unreliable in such cases.

\section{Conclusion}

Direct methods of analysis are potentially more rapid in use and more sensitive to small changes in concentration than methods which involve an initial separation of the substance to be determined, but frequently they are also more susceptible than the latter to undesirable interference. Experience with 
the two methods considered above supports this generalization.

The ammonium phosphate separation procedure may be used to determine magnesium in serum, urine, blood cells, and food or faecal material with only slight modification of the same basic procedure. Moreover, the method is virtually free from interference by other substances occurring in clinical specimens. Undoubtedly the chief disadvantage of this method lies in the two-day period which is required to complete a series of analyses.

The relative speed and sensitivity of the Titan yellow technique make it an attractive procedure for determining magnesium, but unfortunately the method is not highly specific and interference is produced by many substances, both organic and inorganic in nature, which may be encountered in clinical materials. The method is normally suitable for use with serum and urine, but this susceptibility to interference makes it unsatisfactory for the analysis of blood cells, food, and faeces, and may also lead to erroneous results with some pathological samples of serum and urine.

I wish to thank Miss M. Nicholson for assistance.

\section{REFERENCES}

Albright, F., Consolazio, W. V., Coombs, F. S., Sulkowitch, H. W., and Talbott, J. H. (1940). Johns Hopk. Hosp. Bull., 66, 7.

Andreasen, E. (1957). Scand. J. clin. Lab. Invest., $9,138$.

Barker, E. S., Elkinton, J. R., and Clark, J. (1959). J. clin. Invest. $38,1733$.

Baron, D. N. and Bell, J. (1957), J. clin. Path., 10, 280.

Fiske, C. H., and Subbarow, Y. (1925). J. biol. Chem., 66, 375

Gillam, W. S. (1941). Analyt. Chem., 13, 499.

Neill, D. W., and Neely, R. A. (1956). J. clin. Path., 9, 162.

Orange, M., and Rhein, H. C. (1951). J. biol. Chem., 189, 379.

Otto, E. B., and Otto, C. E. (1941). Analyt. Chem., 13, 65.

Simonsen. D. G. Wertman, M., Westover, L. M., and Mehl, J. W. (1946). J. biol. Chem., 166, 747.

Westover, L. M., and Wertman, M. (1947). Ibid., 169, 39. 